\title{
Natural range extension, sampling artifact, or human mediated translocations? Range limits of Northern type Semnopithecus entellus (Dufresne, 1797) (Primates: Cercopithecidae: Colobinae) in peninsular India
}

\author{
Krishnaswamy Sudarshan Chetan Nag ${ }^{1}$, Pramod Padmanabhan ${ }^{2} \&$ Kota Praveen Karanth ${ }^{3}$ \\ ${ }^{1,3}$ Centre for Ecological Sciences, Indian Institute of Science, Bengaluru, Karnataka 560012, India \\ 1,2 Salim Ali Centre for Ornithology and Natural History, Anaikatty Post, Coimbatore,Tamil Nadu 641108, India \\ Email: ${ }^{1}$ chetan@ces.iisc.ernet.in, ${ }^{2}$ pramodpalakkad@gmail.com, ${ }^{3}$ karanth@ces.iisc.ernet.in (corresponding author)
}

Faunal range expansions are dynamic and are of great relevance as they often indicate important changes in habitats due to the profound influence of human intervention, climate change or other environmental variables (Ehrlich et al. 1988; Ohmart 1994; Wehtje 2003; Oden et al. 2004). Variations in species distributions can alter important ecological interactions. Therefore range contractions or expansions may also have economic, management, and safety implications in wildlife management (Darimont et al. 2005). Here we report the range limits of one of

Date of publication (online): 26 August 2011

Date of publication (print): 26 August 2011

ISSN 0974-7907 (online) | 0974-7893 (print)

Editor: Mewa Singh

Manuscript details:

Ms \# 02740

Received 29 March 201

Final received 15 June 2011

Finally accepted 18 July 2011

Citation: Nag, K.S.C., P. Padmanabhan \& K.P. Karanth (2011). Natura range extension, sampling artifact, or human mediated translocations? Range limits of Northern type Semnopithecus entellus (Dufresne, 1797) (Primates: Cercopithecidae: Colobinae) in peninsular India. Journal of Threatened Taxa 3(8): 2028-2032.

Copyright: (c) Krishnaswamy Sudarshan Chetan Nag, Pramod Padmanabhan \& Kota Praveen Karanth 2011. Creative Commons Attribution 3.0 Unported License. JoTT allows unrestricted use of this article in any medium for non-profit purposes, reproduction and distribution by providing adequate credit to the authors and the source of publication.

Acknowledgements: The study was financially supported by the Department of Biotechnology, Government of India (BT/PR-7127/ BCE/08/445/2006) and Ministry of Environment and Forest. We are grateful to the forest departments of Maharashtra, Karnataka, and Andhra Pradesh forest for permissions and cooperation. Special thanks to Chaitra, Achyuthan, Anjana Shenoy, Rishikesh Bahadur Desai, Rish Kumar, Santosh Shanbhag, Sridhar Gadiyar, Kushal Kamble, Harish Bhat Laurens Verwijs, Martin Zaruba, Hanka Svobodova, affiliates of Karanth laboratory for their generous support during the study. We like to thank K.V. Gururaja who helped us with drawing the maps. We also like to thank the reviewers for their constructive comments on the manuscript.

OPEN ACCESS | FREE DOWNLOAD (c) (1) (1)
Abstract: The Semnopithecus entellus can be broadly classified into two morphotypes based on tail carriage, namely the northern and the southern types (NT \& ST). The borderline between these morphotypes runs along the Tapti-Godavari rivers in peninsular India. However there have been anecdotal reports of range extension of NT in peninsular India. To investigate this scenario we undertook an intensive survey of $S$. entellus morphotypes along the borderline districts in the states of Gujarat, Maharashtra, Karnataka and Andhra Pradesh. The GPS coordinates of the two morphotypes were mapped using Maplnfo professional software and the resulting map was compared with the map generated by Roonwal. Results indicate that NT S. entellus range limit fall further south of Roonwal's borderline. This incongruence in NTs distribution between the present study and Roonwal's might be due to natural range extension of NTs in some areas or a product of sampling artifact. Furthermore in parts of Andhra Pradesh and Karnataka human mediated translocations might have also contributed to this range extension.

Keywords: Anthropogenic activity, hybrid zone, peninsular India, range limit, river, tail carriage, under sampling.

the morphotypes of Hanuman Langur Semnopithecus entellus, one of the most widely distributed common species of primate in India.

The Hanuman Langur is a well-known, revered, and extensively studied non-human primate of India. These langurs are known for their habituation to humans and show varied adaptations to urbanization (Pirta et al. 1997; Chauhan \& Pirta 2010; Sharma et al. 2011). They are dispersed throughout most of India and Sri Lanka (Ellerman \& Morrison-Scott 1966; Oates et al. 1994) and are also found in parts of Pakistan, Nepal (Roonwal 1984; Oates et al. 1994; Minhas et al. 2010), Bhutan and Bangladesh (Choudhury 2007). Hanuman langurs are well adapted to a wide range of habitats: from arid regions of Rajasthan to the rainforests of the Western Ghats and in altitudes ranging from the sea level (Nag et al. 2011) to $4270 \mathrm{~m}$ in the Himalaya (Hrdy 1977; Bishop 1978).

Based on tail carriage, Roonwal (1979, 1984) identified two distinct morphotypes among Hanuman 
Langur, namely Northern type (NT) and Southern type (ST). The NT has a tail that loops forward towards the head and is distributed north of the Tapti-Godavari rivers. The ST has a tail that loops backward away from the head and is distributed south of these rivers in peninsular India and Sri Lanka (Roonwal, 1979; 1984) (Fig. 1). These tail loop variations have been reported earlier by Hill (1938) and Rowell (1972). Nevertheless, Roonwal (1984), for the first time gave the exact borderline (here after referred to as Roonwal's line) between the NT and ST which according to him runs along the Tapti-Godavari rivers (see Fig. 1).

There have been several anecdotal evidences suggesting that the range of NT has extended beyond the Roonwal's line but no systematic study has been undertaken to confirm this scenario. Thus to fill this gap we attempted to map the southern limits of the distribution of NTs in peninsular India. Here we report new information that suggests the range limits of NTs in peninsular India and discuss the possible reasons and implications of these range extensional limits.

\section{Methods}

We conducted our survey in peninsular India in the states of Gujarat, Andhra Pradesh, Maharashtra and Karnataka such that the states on either side of the borderline given by Roonwal (1984) were included. Every district along the borderline in each of the states mentioned above was intensively surveyed on foot along roads and trails between June to December 2009 for approximately six months. Surveys were also carried out in jeep and a two wheeler along major roads. All the surveys were carried out by the first author of this paper along with local field assistants provided by the respective state forest departments. In these districts langur troops were located based on information from past surveys (Roonwal 1979, 1984; Kurup 1981, 1984; Srinivasulu \& Nagulu 2001) and also by conversing with the local people. On locating a troop the tail carriage information along with GPS location of the troop were recorded. Tail carriage characters were recorded when the animal was walking casually and not when it was standing or running (as per Roonwal 1984). Troops were typed as NT or ST when all adult members of the troop exhibited either northern or southern type tail carriage respectively. Whereas when both morphotypes were observed in the same troop (mixed troops) they were entered as mostly NT (mNT) or mostly ST (mST) depending on the predominant tail carriage observed. For example a troop was typed as $\mathrm{mNT}$ when $>50 \%$ of its adult members had NT tail carriage. Additionally tail carriage information for troops from adjoining state were also collated from published material (Srinivasulu \& Nagulu 2001; Kumara \& Singh 2004; Kumar et al. 2010; Nag et al. 2011) and information and photographs provided by other researchers in the field. The approximate distributions of these morphotypes were determined by plotting the sampling locations of each morphotype on a map using MapInfo Professional and DIVA-GIS software (Hijmans et al. 2004). On this map Roonwal's line was traced using MapInfo Professional software.

\section{Results}

Results from our survey are shown in Fig. 1, wherein the locations of all NT and ST troops are given by black circles and rectangles respectively. Mixed troops are represented by open circles for $\mathrm{mNT}$ and open triangles for $\mathrm{mST}$. The GPS locations of troops up to $200 \mathrm{~km}$ on either side of Roonwal's line are given in Table 1. As is apparent from Fig. 1, there are up to ten troops to the south of Roonwal's line that consist of langurs with NT tail carriage. Among them two troops in the eastern parts of the range, south of the Krishna River were NTs. Five troops were mNTs and three troops were $\mathrm{mSTs}$. These results suggest that the southern limit of the NT morphotype is further south of Roonwal's line. Furthermore this "range extension" is more pronounced in the south-central and southeastern parts of the NT's distribution. For example according to Roonwal $(1979 ; 1984)$ the southern most limit of NTs along the east coast was Godavari delta north of Krishna River, whereas our observations indicate that they are distributed south of Krishna River in Guntur District of Andhra Pradesh (Fig. 1).

However, up to six troops to the north of Roonwal's line consisted of langurs with ST tail carriage, but these were predominantly $\mathrm{mNT}$. Interestingly these troops were largely restricted to the western end of Roonwal's line near the mouth of Tapti and Narmada rivers (See inset in Fig. 1). In this part of Gujarat, Roonwal (1984) reported the northernmost populations of STs near Surat (bank of Tapti River) and southernmost populations of NT at Bharuch (bank of Narmada River). 


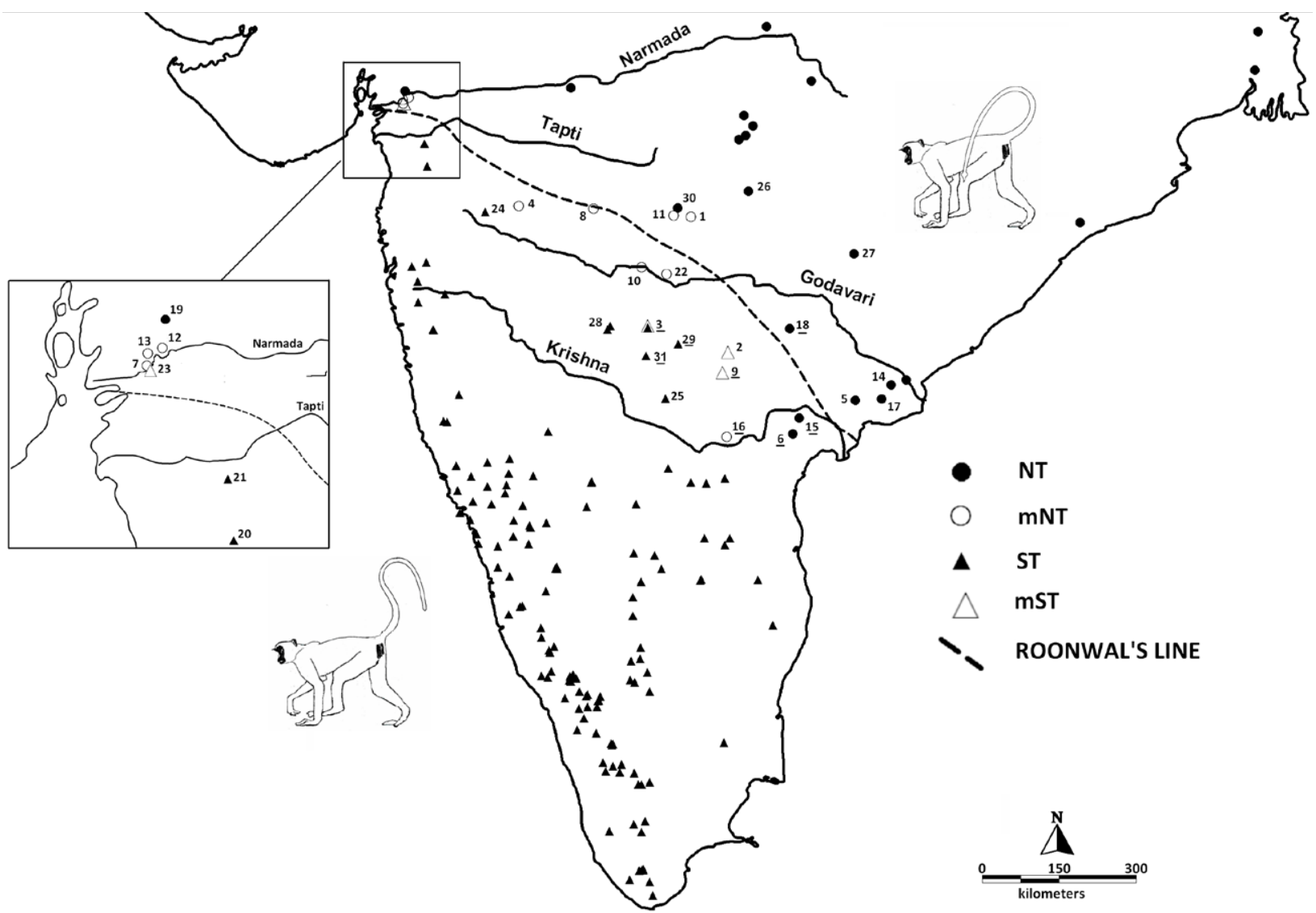

Figure 1. Locations of troops up to $200 \mathrm{~km}$ on either side of Roonwal's line and the tail type observed in these troops. Underlined numbers show locations of areas wherein human mediated translocations of langurs were reported. See Table 1 for the names of these locations.

Our field observations indicate that northernmost population of ST occurs $85 \mathrm{~km}$ north of Surat, in and around Bharuch. Thus Narmada River in the northwest and Krishna River in the southeast form the borderline between the southern and northern types in peninsular India.

\section{Discussion}

Interestingly, there were twice as many troops $(n=10)$ south of Roonwal's line with at least one NT individual than there were troops $(\mathrm{n}=6)$ north of this line with at least one ST individual. Moreover this change in the range of these morphotypes is more extensive in the case of NT, whereas in the STs it is largely confined to western end of Roonwal's line. Additionally in most of the mixed troops $(n=14)$ the predominant tail type is NT $(\mathrm{mNT}=10, \mathrm{mST}=4)$. Preliminary observations also suggest that these mixed troops represent a hybrid zone between NT and ST (Nag et al. 2011). Taken together these patterns are indicative of introgression of NTs into the range of ST.

There are three possible explanations for the incongruence between our observations and those of Roonwal (1984). The first possible scenario is that NTs were always distributed south of Roonwal's line but these areas were poorly /under sampled by Roonwal (1984). Thus our results might reflect the natural range of NTs. Alternately the results reported here might be indicative of range extension of NTs, in some parts, into areas where formerly STs were distributed. This scenario is supported by the largely unidirectional introgression discussed above. Thirdly in parts of Andhra Pradesh and Karnataka the range extension of NTs might be due to human mediated translocations. Translocations of "problem langurs" were reported by forest department and local people around places like Guntur, Nalgonda, Warangal and Medak districts of Andhra Pradesh, and Bidar and Gulbarga districts of Karnataka (see underlined location in Fig. 1). We have also observed two instances of translocations wherein 
Table 1. The GPS locations of troops up to $200 \mathrm{~km}$ on either side of Roonwal's line and the tail type observed in these troops (NT, Northern type; mNT mostly Northern type; ST, Southern type; mST mostly Southern type)

\begin{tabular}{|c|c|c|c|c|c|}
\hline No & Place, District & State & Latitude & Longitude & Tail carriage type \\
\hline 2 & Bhongir, Nalgonda & Andhra Pradesh & 17.51 & 78.888 & $\mathrm{mST}$ \\
\hline 3 & Narasimha Jharna, Bidar & Karnataka & 17.956 & 77.463 & $\mathrm{mST}$ \\
\hline 4 & Ellora caves, Aurangabad & Maharashtra & 20.026 & 75.179 & $\mathrm{mNT}$ \\
\hline 6 & Kotapakonda, Guntur & Andhra Pradesh & 16.142 & 80.039 & NT \\
\hline 7 & Kabirvad, Bharuch & Gujarat & 21.76 & 73.14 & $\mathrm{mST}$ \\
\hline 8 & Lonar, Buldhana & Maharashtra & 19.977 & 76.508 & $\mathrm{mNT}$ \\
\hline 9 & Wailpally, Nalgonda & Andhra Pradesh & 17.158 & 78.788 & $\mathrm{mST}$ \\
\hline 13 & Nikora, Bharuch & Gujarat & 21.77 & 73.14 & $\mathrm{mNT}$ \\
\hline 14 & Rajamundry, East Godavari & Andhra Pradesh & 16.983 & 81.783 & NT \\
\hline 15 & Sattenapalle, Guntur & Andhra Pradesh & 16.415 & 80.153 & NT \\
\hline 16 & Srisailam, Kurnool & Andhra Pradesh & 16.087 & 78.874 & $\mathrm{mST}$ \\
\hline 17 & Tanuku, West Godavari & Andhra Pradesh & 16.745 & 81.616 & NT \\
\hline 18 & Pakhal Dam, Warangal & Andhra Pradesh & 17.95 & 79.988 & NT \\
\hline 19 & Baroda, Baroda & Gujarat & 22.306 & 73.187 & NT \\
\hline 25 & Koilkonda, Mahbubnagar & Andhra Pradesh & 16.742 & 77.723 & ST \\
\hline 26 & Tadoba, Chandrapur & Maharashtra & 20.266 & 79.163 & NT \\
\hline 27 & Indravati National Park, Dantewada & Chattisgarh & 19.233 & 81.011 & NT \\
\hline 28 & Kasar Sirsi, Latur & Maharashtra & 17.95 & 76.746 & ST \\
\hline 29 & Kothlapur, Medak & Andhra Pradesh & 17.675 & 77.951 & ST \\
\hline 30 & Mahur, Nanded & Maharashtra & 19.847 & 77.923 & NT \\
\hline 31 & Sedam, Gulburga & Karnataka & 17.376 & 77.585 & ST \\
\hline
\end{tabular}

NTs were caught around Guntur and later released into Srisailam forests.

Interestingly, the range of NT Hanuman Langur overlaps with that of Rhesus Macaque Macaca mulatta in India and among Rhesus Macaques too there have been reports of range extension. Here again, the range extension of Rhesus Macaques is mostly into the northern parts of the state of Andhra Pradesh in and around Srisailam (Kumar et al. 2011). These observations hint at a common underlying mechanism driving range extensions in these two sympatric primate species. Interestingly, Kumar et al. (2011) also invoke natural process as well as human introductions for range extension in Rhesus Macaques. We believe that a detailed behavioral, ecological and genetic study of the hybrid zone between the two morphotypes of Hanuman Langurs might help us better understand this pattern.

\section{REFERENCES}

Bishop, N.H. (1978). Langurs living at high altitudes. Journal of the Bombay Natural History Society 74: 518-520.

Chauhan, A. \& R.S. Pirta (2010). Socio-ecology of two 
species of non-human primates, Rhesus Monkey (Macaca mulatta) and Hanuman Langur (Semnopithecus entellus), in Shimla, Himachal Pradesh. Journal of Human Ecology 30(3): 171-177.

Choudhury, A.U. (2007). The eastern limit of distribution of the Hanuman Langur Semnopithecus entellus Dufresene. Journal of the Bombay Natural History Society 104: 199 200.

Darimont, C.T., P.C. Paquet, T.E. Reimchen, V. Crichton (2005). Range expansion by moose into coastal temperate rainforests of British Columbia, Canada. Diversity \& Distribution 11: 235-239.

Ellerman, J.R. \& T.C.S. Morrison-Scott (1966). Checklist of Palaearctic and Indian Mammals, pp. 1758-1946, $2^{\text {nd }}$ Edition. Trustees of the British Museum (Natural History), London, 810pp.

Elrcih, P.R., D.S. Dobkin \& D. Wheye (1988). Range Expansion. University of Stanford. (Essay available at http://www.stanford.edu/group/stanfordbirds/text/essays/ Range_Expansion.html).

Hrdy, S.B. (1977). The Langurs of Abu-Female and Male Strategies of Reproduction. Harvard University Press, Cambridge, 361pp.

Hill, W.C. (1938). The mode of carrying the tail in leafmonkeys. Ceylon Journal of Science (B) 21: 66-67.

Hijmans, R.J., L. Guarino, C. Bussink, P. Mathur, M. Cruz, I. Barrentes \& E. Rojas (2004). DIVA-GIS. Vsn. 5.0. A geographic information system for the analysis of species distribution data. (manual available at: http://www.divagis.org).

Kumar, R., S. Radhakrishna \& A. Sinha (2011). Of Least Concern? Range Extension by Rhesus Macaques (Macaca mulatta) Threatens Long-Term Survival of Bonnet Macaques (M. radiata) in Peninsular India. International Journal of Primatology 32: 945-959.

Kumara, H.N. \& M. Singh (2004). Distribution and abundance of primates in rain forests of the Western Ghats, Karnataka, India and the conservation of Macaca silenus. International Journal of Primatology 25(5): 1001-1018.

Kumara, H.N., S. Kumar \& M. Singh (2010). Of how much concern are the 'least concern' species? Distribution and conservation status of Bonnet Macaques, Rhesus Macaques and Hanuman Langurs in Karnataka, India. Primates 51: 37-42.

Kurup, G.U. (1981). Report on the census surveys of rural and urban populations of Non-Human Primates of south India, Zoological Survey of India, Calicut.

Kurup, G.U. (1984). Census survey and population ecology of Hanuman Langur, Presbytis entellus (Dufresne, 1797) in south India. Proceedings of Indian National Science Academy 50: 245-256.

Minhas, R.A., K.B. Ahmed., M.S. Awan \& N.I. Dar (2010). Social organization and reproductive biology of Himalayan Grey Langur (Semnopithecus entellus ajax) in Machiara National Park, Azad Kashmir (Pakistan). Pakistan Journal of Zoology 42(2): 143-156.

Nag, K.S.C., P. Pramod \& K.P. Karanth (2011). Taxonomic implications of a field study of morphotypes of Hanuman Langurs (Semnopithecus entellus) in peninsular India. International Journal of Primatology 32: 830-848.

Oates, J.F., A.G. Davies \& E. Delson (1994). The diversity of living colobines, pp. 45-73 In: Davies, A.G. \& J.F. Oates (eds.). Colobine Monkeys: Their Ecology, Behaviour and Evolution. Cambridge University Press, Cambridge, $415 \mathrm{pp}$.

Oden, J.D., N.L. Poff, M.R. Douglas, M.E. Douglas \& K.D. Fausch (2004). Ecological and evolutionary consequences of biotic homogenizations. Trends in Ecology and Evolution 19: $18-24$.

Ohmart, R.D. (1994). The effects of human-induced changes on the avifauna of western riparian habitats. Studies in Avian Biology 15: 273-185.

Pirta, R.S., M. Gadgil \& A.V. Kharshikar (1997). Management of the Rhesus Monkey Macaca mulatta and Hanuman Langur Presbytis entellus in Himachal Pradesh, India. Biological Conservation 79: 97-106.

Roonwal, M.L. (1979). Field study of geographical, sub specific and clinal variations in tail carriage in the Hanuman Langur, Presbytis entellus (primates) in South Asia. Zoologischer Anzeiger, Jena 202: 235-255.

Roonwal, M.L. (1984). Tail form and carriage in Asian and other primates, and their behavioral and evolutionary significance, pp. 93-151. In: Roonwal, M.L., S.M. Mohnot $\&$ N.S. Rathore (eds.). Current Primate Research. Jodhpur University Press, India, 627pp.

Rowell, T. E. (1972). Social Behaviour of Monkeys. Cox and Wyman, London, 203pp.

Srinivasulu, C. \& V. Nagulu (2001). Status of Primates in Andhra Pradesh. Envis Bulletin: Wildlife and Protected Areas 1(1): 109-112.

Sharma, G., C. Ram, Devilal \& L.S. Rajpurohit (2011). Study of man-monkey conflict and its management in Jodhpur, Rajasthan (India). Journal of Evolutionary Biology Research 3(1): 1-3.

Wehtje, W. (2003). Range expansion of the Great-tailed Grackle. Journal of Biogeography 30: 1593-1607. 